\title{
Hypofractionated Radiotherapy in the Treatment of Early Glottic Carcinoma
}

\author{
${ }^{1}$ Arif Jamshed, ${ }^{2}$ Raza Hussain, ${ }^{3}$ Khaliq UR Rehman, ${ }^{4}$ Hassan Iqbal, ${ }^{3}$ Muhammad Ali, ${ }^{5}$ Sarah Jamshed \\ ${ }^{6}$ Natasha Hameed, ${ }^{1}$ Uzma Majeed, ${ }^{1}$ Shahid Hameed \\ ${ }^{1}$ Consultant, Department of Radiation Oncology, Shaukat Khanum Memorial Cancer Hospital and Research Centre, Lahore, Pakistan \\ ${ }^{2}$ Consultant, Department of Surgery, Shaukat Khanum Memorial Cancer Hospital and Research Centre, Lahore, Pakistan \\ ${ }^{3}$ Resident, Department of Radiation Oncology, Shaukat Khanum Memorial Cancer Hospital and Research Centre, Lahore, Pakistan \\ ${ }^{4}$ Resident, Department of Surgery, Shaukat Khanum Memorial Cancer Hospital and Research Centre, Lahore, Pakistan \\ ${ }^{5}$ Medical Student, Aga Khan Medical University, Karachi, Pakistan \\ ${ }^{6}$ Medical Student, Lahore Medical and Dental College, Lahore, Pakistan
}

Correspondence: Arif Jamshed, Consultant, Department of Radiation Oncology, Shaukat Khanum Memorial Cancer Hospital and Research Centre, Lahore, Pakistan, e-mail: jamshedarif@ hotmail.com

\begin{abstract}
Introduction: Given the high probability of cure, the aims of treatment are cure, laryngeal preservation and good voice quality while making effective use of available resources. In this study we analyze locoregional control (LRC) and survival following hypofractionated radiotherapy in early stage glottic squamous cell carcinoma treated at Shaukat Khanum Memorial Cancer Hospital and Research Center.

Materials and methods: Between October 2003 and J une 2009, 87 patients with early glottic squamous cell carcinoma were treated with hypofractionated radiotherapy. All patients were included in the study (M: 94\%; F:6\%). Median age was 60 years (range: $21-81$ years). Sixty-six percent of patients were smokers. AJ CC stage was T1 in $95 \%$ and T2 in $5 \%$ of the patients. Radiotherapy dose was 55 Gy in 20 fractions over 4 weeks. All patients were treated on cobalt-60. Median radiotherapy treatment time was 28 days (range: $23-35$ days).

Results: The LRC rate after primary radiotherapy at 5 years was $91 \%$ (95\% CI: 88-94\%). The 5 years overall and disease-specific survival was 86\% (95\% Cl: 81 and 91\%) and 97\% (CI 95\%: 95 and 99\%) respectively. Patients with Tla and T1b disease had LRC rates of 95 and $88 \%(p=0.32)$. The LRC rates for patients with and without anterior commissure involvement at 5 years were 80 and $96 \%(p=0.02)$ respectively.

Conclusion: Hypofractionated radiotherapy $55 \mathrm{~Gy}$ in 20 fractions is comparable to conventional fractionation schedules in terms of locoregional control and survival while offering potential for optimizing resources usage.
\end{abstract}

Keywords: Larynx, Radiotherapy.

\section{INTRODUCTION}

Glottis, the hub of voice production accounts for $60-65 \%$ of all laryngeal carcinoma. ${ }^{1}$ Squamous cell carcinoma is the predominant histological type and nearly $40 \%$ of the patients present with stage III and IV disease at the time of initial evaluation. ${ }^{2}$ Patients with early squamous cell carcinoma of the laryngeal glottis are generally considered to have good prognosis. ${ }^{3,4}$ The aims of treatment for early glottis cancer are cure, laryngeal voice preservation, optimal voice quality with minimal morbidity, expense and inconvenience. ${ }^{5} \mathrm{~W}$ hile surgery and radiotherapy are equally effective and both highly successful in the management of early vocal cord cancer, the treatment of choice remains controversial as the evidence base for most decisions is derived from nonrandomized studies. ${ }^{6}$ Radiotherapy is generally the favored treatment in most centers despite comparable cure rates for selected $T 1$ and $T 2$ glottis tumors with laser excision, cordectomy and hemilaryngectomy. The preference of radiotherapy over surgery stems from a less restrictive selection criteria, better quality of voice and comparable local control and survival rates. ${ }^{3}$ L ocal control rates with radiotherapy in early glottic cancer show considerable variation that range from approximately 80 to $95 \%$ for patients with T1 cancers and from 50 to $80 \%$ for those with $\mathrm{T} 2$ lesions. ${ }^{7,8}$

Worldwide a range of radiation fractionation policies exists for the treatment of early laryngeal cancer. W hile most centers have adopted conventional $2 \mathrm{~Gy}$ fractionation for 6 to 7 weeks, others use hypofractionated regimens with shorter overall time. ${ }^{7-9} \mathrm{~A}$ theoretical benefit of hypofractionation is that treatment is completed before accelerated repopulation becomes a significant radiobiological factor. In addition, hypofractionated schedules with reduced number of fractions allow for a more efficient use of resources and are advantageous in countries with limited radiation facilities. In this study, we analyze locoregional control (LRC) and survival following hypofractionated radiotherapy in early squamous cell carcinoma of the laryngeal glottis at Shaukat K hanum M emorial Cancer Hospital and Research Centre (SK M CH and RC). 


\section{PATIENTS AND METHODS}

The head and neck unit prospective database collects data on all patients with head and neck malignancies treated at SK M CH and RC. The database identified 87 patients with $\mathrm{T} 1$ and $\mathrm{T} 2$ squamous cell carcinoma of the true vocal cord treated with radical hypofractionated radiation between October 2003 and J une 2009. A Il patients were included in the study. Demographics, clinical, pathological and treatment variables were extracted from the database and electronic medical records. All pathology material was reviewed at SK M CH and RC. Each patient was seen in the joint head and neck clinic prior to treatment and primary disease was assessed by a comprehensive examination of the head and neck and fiberoptic nasoendoscopy. A CT or $M R I$ scan of the neck and chest radiographs was obtained. Tumors were staged according to the AJCC 6th edition (A merican J oint Commission on Cancer).

\section{Radiotherapy}

Patients were simulated and treated in a beam-directed shell with conventional planning in the supine position with two wedged opposing lateral beams, at $2.75 \mathrm{~Gy}$ per day 5 days a w eek to a total dose of $55 \mathrm{~Gy}$ in 20 fractions on cobalt-60 teletherapy machine. The radiation field borders were superior border passing above the hyoid bone, inferior border at the bottom of the cricoid cartilage, posterior border passing through middle of vertebral bodies but keeping offcord and falling off $1.5 \mathrm{~cm}$ anteriorly. Field size ranged from $5 \times 5 \mathrm{~cm}$ to $6 \times 6 \mathrm{~cm}$ and these borders were kept constant for all patients, and treatment fields were neither reduced nor increased at any point during the treatment course. The dose was prescribed at isocenter that just lieinside the tumor volume encompassing 95 to $105 \%$ isodose lines. Field verification films were obtained for each field at the start and during the course of treatment at weekly intervals. Patients were followed up on weekly basis during radiotherapy.

\section{Assessment of Response}

Response to radiation was assessed at 6 weeks after completion of therapy by examination of head and neck and fiberoptic nasendoscopy. Posttreatment patients were followed up at 3 to 4 monthly intervals during first 2 years and 6 monthly thereafter. Patients with suspected recurrent disease were restaged with CT/M R I scan of neck and biopsy.

\section{Statistical Analysis}

Statistical package for social sciences, version 10 was used for statistical analysis. LRC was our primary end point with secondary end points being overall survival (OS) and disease-specific survival (DSS). LRC was defined as the time interval from the date of start of radiation until date of loco-regional failure or censored at date of death if patient died from noncancerous reason but without relapse, or date last seen if alive and relapse free. DSS was calculated until death date if patient died from laryngeal carcinoma, otherwise censored at the date of death due to noncancerous reasons or alive on last follow-up date. OS was calculated from starting date of radiotherapy till the death date for those who died or censored at the last follow-up date seen alive. Survival curves were obtained according to K aplan-M eier method and $95 \%$ confidence intervals for survival estimates were calculated. Overall treatment time was defined as number of days from the commencement to the completion of radiotherapy.

\section{RESULTS}

Patient characteristics are shown in Table 1. All patients received the planned dose of $55 \mathrm{~Gy}$ in 20 fractions except one patient who received $52.25 \mathrm{~Gy}$ in 19 fractions.

At the time of last follow-up, 79 patients are alive and free of disease. Median follow-up was 2.63 years (range: 0.9-5.6 years). Causes of death were local recurrence $(n=2)$, second primary cancer $(n=2)$ and intercurrent diseases $(n=4)$ (Table 2$)$. Seven patients relapsed after radiation treatment. Local failure according to $T$ stage was seen in $6 \%(5 / 83)$ of patients with $\mathrm{T} 1$ and $50 \%$ of patients with $\mathrm{T} 2$ disease (2/4). The site of relapse was larynx in all cases and no patient failed either in the neck nodes or distant site. All relapses occurred within the first 2 years. One patient aged 81 years refused laryngectomy and was lost to follow-up and is presumed to have died of disease. Six patients underwent salvage laryngectomy. O ne patient developed stomal recurrence and died. The remaining five patients following laryngectomy remain alive and free of disease at the time of last follow-up (Table 3).

Table 1: Patient characteristics $(n=87)$

$\begin{array}{ll}\text { Characteristics } & n(\%) \\ \text { Gender } & \\ \text { Male } & 82(94) \\ \text { Female } & 5(6) \\ \text { Age (years) } & \\ \text { Median } & 60 \text { years } \\ \text { Range } & 21-81 \text { years } \\ \text { Smoking } & \\ \text { Yes } & 57(66) \\ \text { No } & 30(34) \\ \text { AJCC T Stage } & \\ \text { T1a } & 66(75) \\ \text { T1b } & 17(20) \\ \text { T2 } & 4(5) \\ \text { Histology } & \\ \text { Squamous cell carcinoma } & 87(100) \\ \text { Grade } & \\ \text { Well } & 50(58) \\ \text { Moderate } & 35(40) \\ \text { Poor } & 2(2) \\ \text { Overall treatment time } & \\ \text { Median } & 28 \\ \text { Range } & 23-35 \text { days } \\ \end{array}$


Table 2: Causes of death

\begin{tabular}{|c|c|c|c|c|c|}
\hline No. & Age & Gender & Stage & Survival time (months) & Cause of death \\
\hline 1 & 48 & $M$ & $\mathrm{~T} 1 \mathrm{~b}$ & 32 & Ischemic heart disease \\
\hline 2 & 81 & $\mathrm{M}$ & $\mathrm{T} 1 \mathrm{~b}$ & 16 & Carcinoma larynx \\
\hline 3 & 62 & $M$ & T1a & 35 & Carcinoma lung \\
\hline 4 & 66 & $M$ & T1a & 23 & Ischemic heart disease \\
\hline 5 & 68 & $\mathrm{M}$ & $\mathrm{T} 1 \mathrm{a}$ & 10 & Carcinoma larynx \\
\hline 6 & 66 & M & T1a & 2 & Carcinoma lung \\
\hline 7 & 81 & M & T1a & 5 & Ischemic heart disease \\
\hline 8 & 61 & $M$ & T1a & 40 & Ischemic heart disease \\
\hline
\end{tabular}

\begin{tabular}{|c|c|c|c|c|c|c|c|}
\hline No. & Age & Gender & Stage & Site of failure & $\begin{array}{l}\text { Time to failure } \\
\text { (months) }\end{array}$ & Salvage treatment & $\begin{array}{l}\text { Status at last } \\
\text { follow-up }\end{array}$ \\
\hline 1 & 50 & $M$ & T2 & Local & 11 & TL & Alive with no disease \\
\hline 2 & 78 & $M$ & T2 & Local & 17 & TL & Alive with no disease \\
\hline 3 & 60 & $M$ & $\mathrm{~T} 1 \mathrm{~b}$ & Local & 14 & $\mathrm{TL}$ & Alive with no disease \\
\hline 4 & 40 & $M$ & $\mathrm{~T} 1 \mathrm{a}$ & Local & 19 & $\mathrm{TL}$ & Alive with no disease \\
\hline 5 & 60 & $M$ & $\mathrm{~T} 1 \mathrm{a}$ & Local & 10 & $\mathrm{TL}$ & Alive with no disease \\
\hline 6 & 81 & $M$ & $\mathrm{~T} 1 \mathrm{~b}$ & Local & 16 & None & Dead \\
\hline 7 & 68 & $M$ & $\mathrm{~T} 1 \mathrm{a}$ & Local & 6 & $\mathrm{TL}$ & Dead \\
\hline
\end{tabular}

TL: Total laryngectomy

Table 4: Locoregional control rates

5 -year locoregional $\quad p$-value
control rates

\begin{tabular}{|c|c|c|}
\hline All (87) & 91 & \\
\hline $\begin{array}{l}\text { Age } \\
<50(28) \\
>50(59)\end{array}$ & $\begin{array}{l}91 \\
90\end{array}$ & 0.80 \\
\hline $\begin{array}{l}\text { Sex } \\
\text { Males (82) } \\
\text { Females (5) }\end{array}$ & $\begin{array}{c}90 \\
-\end{array}$ & 0.55 \\
\hline $\begin{array}{l}\text { Smoking } \\
\text { Yes (57) } \\
\text { No (30) }\end{array}$ & $\begin{array}{l}90 \\
92\end{array}$ & 0.78 \\
\hline $\begin{array}{l}\text { Stage T1 } \\
\text { T1a (66) } \\
\text { T1b (17) }\end{array}$ & $\begin{array}{l}95 \\
88\end{array}$ & 0.32 \\
\hline $\begin{array}{l}\text { AC involvement } \\
\text { Involved (83) } \\
\text { Not involved (4) }\end{array}$ & $\begin{array}{l}80 \\
96\end{array}$ & 0.02 \\
\hline $\begin{array}{l}\text { Grade } \\
\text { Well (50) } \\
\text { Moderate (35) } \\
\text { Poor (2) }\end{array}$ & $\begin{array}{c}93 \\
86 \\
100\end{array}$ & 0.60 \\
\hline $\begin{array}{l}\text { Overall treatment time } \\
\leq 28 \text { days }(57) \\
>28 \text { days }(30)\end{array}$ & $\begin{array}{l}89 \\
92\end{array}$ & 0.69 \\
\hline
\end{tabular}

AC: Anterior commissure

The $L R C$ rate after primary radiotherapy at 5 years was 91\% (95\% Cl: 88-94\%) (Fig. 1). The 5-year OS and DSS was $86 \%(95 \% \mathrm{Cl}: 81$ and $91 \%)$ and $97 \%$ (Cl 95\%: 95 and 99\%) respectively (Figs 2 and 3). Patients with T1a and T1b disease had locoregional control rates of 95 and $88 \%$ $(p=0.32$ ) (Fig. 4). Of the 27 patients with anterior commissure (AC) involvement five had local relapse. In
Table 5: Factors influencing locoregional control in early laryngeal cancer

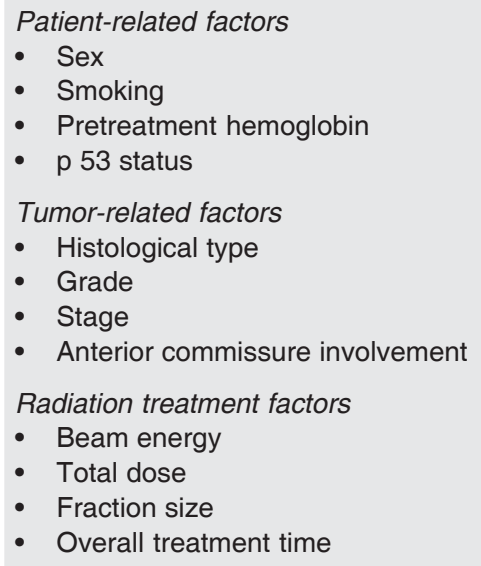

the remaining 60 patients without $A C$ involvement, two patients had local recurrence. The LRC rates for patients with and without $A C$ involvement at 5 years were 80 and $96 \%(p=0.02)$ respectively (Fig. 5$)$.

Radiation treatment was completed within 28 days in 57 patients (65\%) (range: $23-35$ days). M ost of the radiation treatment delays were due to either machine breakdown or public holidays. The locoregional control rates for patients completing radiotherapy in $\leq 28$ days versus $>28$ days were 90 and $92 \%$ respectively. $L R C$ rates according to patient, tumor- and treatment-related factors are presented in Table 4.

A ssessment of voice quality was performed in 76 patients via telephonic interview. Eighty-two percent of the patients were satisfied with their voice after treatment. The remaining 


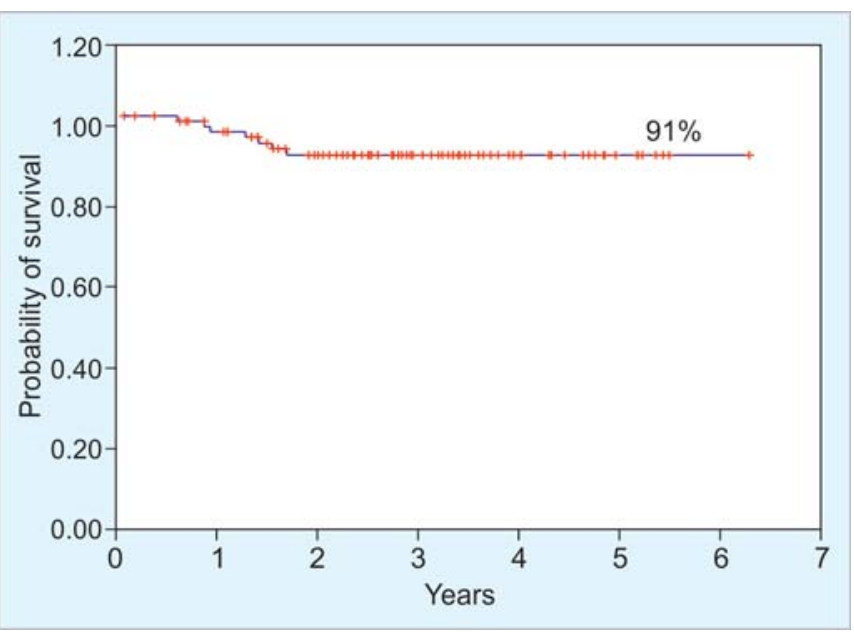

Fig. 1: Locoregional control

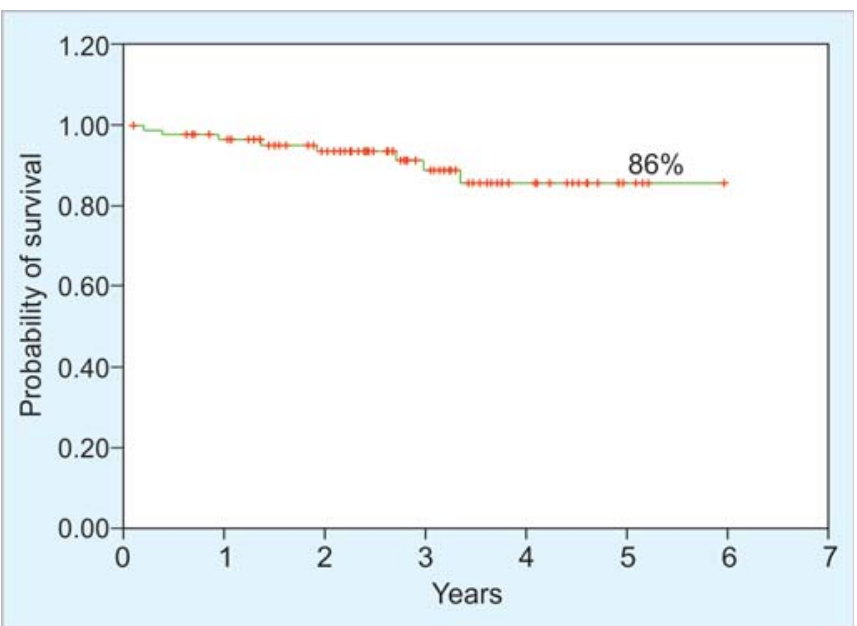

Fig. 2: Overall survival

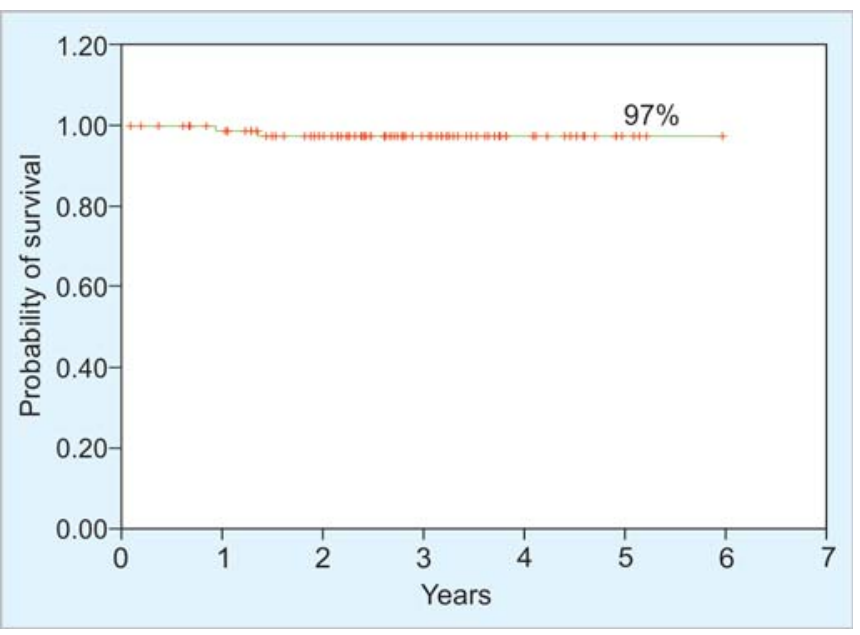

Fig. 3: Disease-specific survival

$18 \%$ did not appreciate any improvement in the quality of speech after radiotherapy. Radiation chondronecrosis and grade 3/4 laryngeal edema did not develop in any patient.

\section{DISCUSSION}

The outcome of early squamous cell carcinoma of the true vocal cord treated with radiotherapy is influenced by several

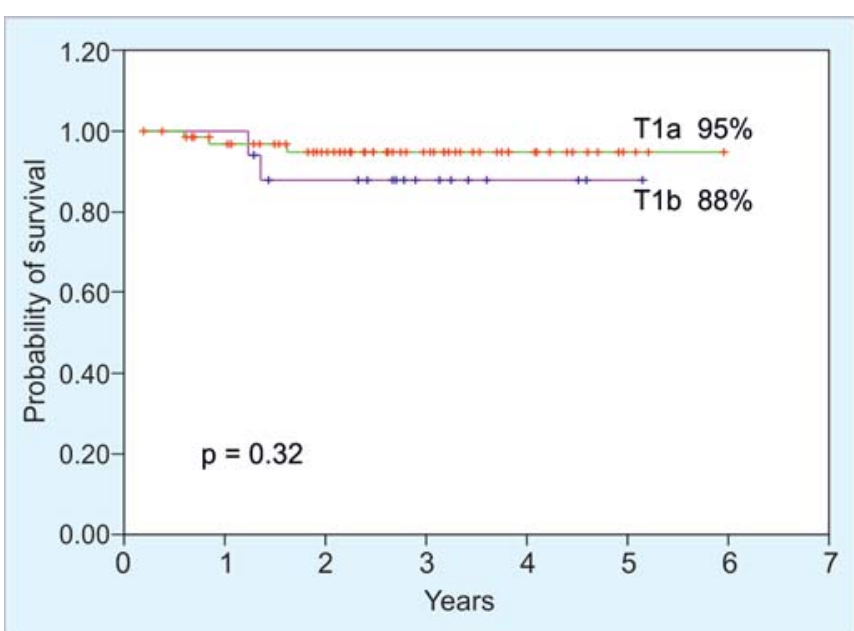

Fig. 4: Locoregional control in stages $\mathrm{T} 1 \mathrm{a}$ and $\mathrm{T} 1 \mathrm{~b}$

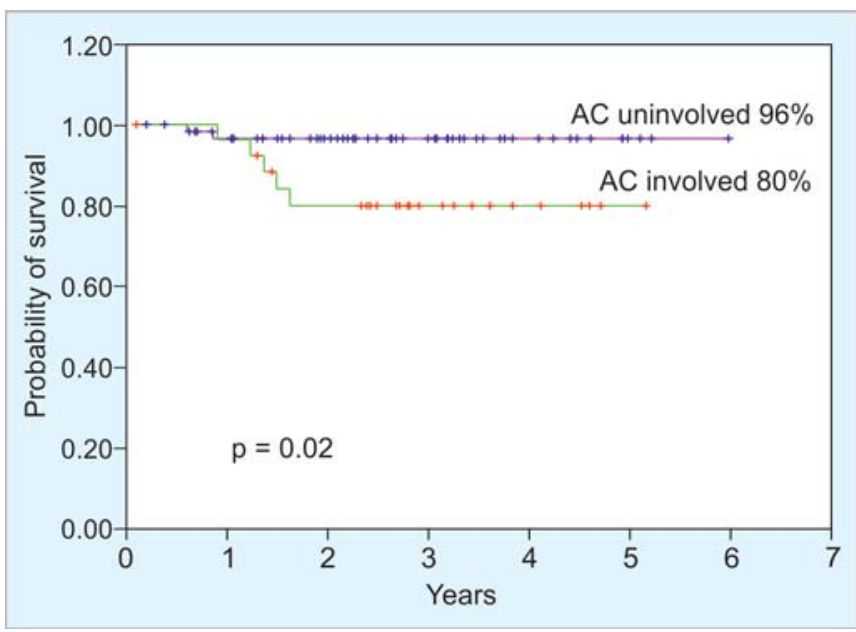

Fig. 5: Locoregional control in patients with and without anterior commissure $(A C)$ involvement

patient, tumor- and treatment-related factors (T able 5). The prognosis of females in head and neck cancer is believed to be similar or better than males and the reasons for this observation are unexplained. In our series none of the five women failed treatment. Smokers particularly those who continue to smoke after treatment are considered to have a worse LRC. ${ }^{10}$ However, no such difference was observed in our patients. The chances of cure with radiotherapy decrease with increasing T stage. A ccording to the AJCC staging system $T 1$ glottis carcinoma is divided into two subgroups, T la tumor involving one vocal cord (may involve anterior or posterior commissure) and $\mathrm{T} 1 \mathrm{~b}$ tumor involving both the vocal cords. With tumors confined to the vocal cord the incidence of nodal metastasis ranges from 0 to $2 \%$. In more advanced lesions $\mathrm{T} 2$ and $\mathrm{T} 3$ the incidence increases from 10 to $15 \%$ respectively. ${ }^{11}$ L ocal control rates for $\mathrm{T} 1$ glottis cancer treated with radiation vary between 80 and $95 \%$ and with surgical salvage ultimate local control rates are between 90 to $100 \%$. Patients with stage T $1 b$ lesions are considered to have a lower local control rates compared with T 1a tumors. ${ }^{12-14}$ In a series covering 449 patients local control rates for $T 1$ a and $T 1$ b was 91 and $82 \%$ respectively. ${ }^{12}$ How ever, other authors similar to our report have failed to 
show such difference in LRC for T1 lesions. ${ }^{5,15}$ The management plans for $\mathrm{T} 2$ carcinoma of the glottis remain controversial and with wide variations. In general T2 lesions have poor cure rates then $\mathrm{T} 1$ lesions. The local control rate for T2 squamous cell carcinoma of the glottis with conventional radiotherapy is approximately 71 to $85 \%$ and salvage rate for local radiation failure is 88 to $95 \% .{ }^{7}$ O ur series had only four patients with $\mathrm{T} 2$ tumors and this small number reflects the institutional practice of treating these patients with conventional fractionation encompassing the primary site and upper neck with radiation treatment portals. A mong the four patients with T2 tumors, two had local failure at 9 and 14 months following treatment that were salvaged with laryngectomy.

The prognostic value of $A C$ involvement on recurrence is controversial. A review of approximately 2200 stage I patients with glottic carcinoma showed no increase in local failure with $A C$ involvement. ${ }^{16}$ Other studies indicate that AC involvement is a poor prognostic variable for local control with both radiotherapy and surgery. ${ }^{4,17}$ Our results support the notion of poor prognosis for patients with $A C$ involvement.

The potential risk of prolonged overall radiotherapy treatment time in head and neck cancer is w ell documented. Prolonged overall radiotherapy treatment time has a negative impact on LRC and survival. ${ }^{18} \mathrm{R}$ udoltz et al reported $100 \%$ local control when radiotherapy was completed within 42 days, in contrast to $50 \%$ local control when treatment lasted from 55 to 66 days. ${ }^{19}$ Fein et al in their study reported a lower local control rate when radiation was extended for more then 50 days in the management of T1-T2 glottic carcinoma. ${ }^{15}$ Interruptions in the treatment can be caused by machine breakdown, holidays or patient-related factors. A $n$ audit by Royal College of Radiologists of radical radiotherapy for head and neck cancer showed $81 \%$ of treatment interruptions were due to machine breakdow $\mathrm{n}$ or servicing. ${ }^{20}$ Fraction size may influence local control rates. $M$ any studies have demonstrated better local control rates if fraction size is $\geq 2 \mathrm{~Gy} .{ }^{21-25}$ Short et al reported $95 \%$ locoregional control with accelerated hypofractionated regimen $52.5-55$ G y over 4 weeks compared with $75 \%$ when treating with 60-66 Gy over 6-6.5 weeks $(p=0.002) .{ }^{21}$ In another study covering 171 patients control rate was significantly improved using $2 \mathrm{G}$ y than $1.8 \mathrm{G}$ y per fraction. ${ }^{23}$ Patients treated with higher fraction size $>3 \mathrm{~Gy}$ have a higher risk of developing late complications and this is in contrast to the findings of the BIR trial. ${ }^{10,25}$

The optimum beam energy advocated for the management of early glottic carcinoma is cobalt-60 or 4-M V photons. ${ }^{16}$ The basis for advocating lower beam energy is the fact that high energy photons lead to inadequate build up in the anterior commissure due to thin wedge shape of the midline of the neck. Dosimetry studies to calculate the degree of under dosage have yiel ded conflicting results.
The dose absorbed in the anterior commissure decreased by $12 \%$ with $6-M V$ photons and $18 \%$ with $10-M V$ photons when compared with cobalt- $60 .{ }^{26} \mathrm{~A}$ kaine et al reported on 154 patients with stage T1 tumors treated with 6-M V; the 5 -year local control rate with and without anterior commissure involvement was $81 \%$ (27 patients) and 91\% (127 patients) respectively. W hile the result did not reach statistical significance, it does invoke clinical concern. ${ }^{27}$ Conversely data from other retrospective studies suggest that the estimated 5-year local control rates with 6-, 8-, $10-\mathrm{MV}$ photons may be similar to those achieved with cobalt- $60 .{ }^{28}$

Various studies have indicated that endoscopic laser excision produces oncologic outcome and voice quality comparable to radiotherapy treatment. ${ }^{29} \mathrm{~W}$ hile radiation is often favored as it appears to be associated with reduced impairment of voice quality, but qualitative studies about vocal function in postirradiated patients have been inconclusive and not uniform..$^{29-32}$ Dinapoli et al reported on 143 patients with $\mathrm{T} 1 \mathrm{gl}$ ottis cancer; 73 underwent surgery and 70 underwent radiotherapy. No statistically significant differences were found between the two groups in terms of overall survival and disease-free survival. V oice quality was eval uated using the $\mathrm{VHI}$ questionnaire and better scores for each category in the $\mathrm{VHI}$ were found for patients receiving radiotherapy compared with surgery. ${ }^{33}$ In our patients while no formal assessment of voice quality was performed, a telephonic interview was conducted among survivors with intact larynx to document patient's satisfaction with voice quality. Over two-third of the patients appreciated an improvement in their pretreatment speech and expressed satisfaction with the quality of their voice.

\section{CONCLUSION}

The less restrictive selection criteria for patient selection compared to surgery, comparable local control rates, favorable voice outcome and effective resource sparing provide a distinct advantage for hypofractionated radiotherapy in the treatment of early laryngeal cancer over other treatment strategies. The optimum radiation schedule remains to be defined and together with formal voice quality assessment should be the subject of future prospective trials.

\section{REFERENCES}

1. Ferlay J, B ray F, Pisani P, Parkin D M. G lobocan 2000: Cancer incidence, mortality and prevalence worldwide. V ersion 1. Cancer base No. 5. Lyon: IA RC Press 2001.

2. M yers EN, Suen JY, M yers J N, H anna EO. Cancer of the head and neck (4th ed). Philadelphia, PA, Saunders 2003.

3. M illion RR, Cassisi NJ, M ancuso AA . Larynx. In: M illion RR, Cassisi NJ (Eds). M anagement of head and neck cancer, a multidisciplinary approach (2nd ed). Philadelphia: J B L ippincott 1994;431-97.

4. Kaiser TN, Spector GJ. Tumors of the Iarynx and laryngopharynx. In: Ballanger JJ (Ed). Diseases of the nose, 
throat, ear, head and neck (14th ed). Philadelphia: Lea and Febiger; 1991;pp. 682-746.

5. M endenhall W M , A mdur RJ, M orris CG, Hinerman RW . T1T2N 0 squamous cell carcinoma of the glottic larynx treated with radiation therapy. J Clin Oncol 2001;19:4029-36.

6. Pfister DG, L aurie SA, W einstein GS, et al. A merican Society of Clinical Oncology: Clinical practice guidelines for the use of larynx preservation strategies in the treatment of laryngeal cancer. J Clin Oncol 2006;24(22):3693-704.

7. M endenhall W M, Parsons JT, M illon RR, Fletcher GH. T1-T2 squamous cell carcinoma of the glottis larynx treated with radiation therapy: Relationship of dose fractionation factors to local control and complications. Int J Radiat Oncol Biol Phys 1988;15:1267-73.

8. M endenhall WM, Parsons JT, Stringer SP, Cassissi N J. $M$ anagement of Tis, T1, T2 squamous cell carcinoma of the glottic larynx. A nn J Otolaryngol 1994;15:250-57.

9. Williams MV, J ames ND, Summers ET, et al. N ational survey of radiotherapy fractionation practice in 2003. Clinical Oncol 2006;18:3-14.

10. V an der V oet J C, K eus RB, H art AA, Hilgers FJ, B artelink H. The impact of treatment time and smoking on local control and complications in T1 glottic cancer. IntJ Radiat Oncol Biol Phys 1998;42:247-55.

11. W ang CC. Radiation therapy for head and neck neoplasms (2nd ed). Y ear B ook M edical Publishers, Inc; 1990;pp. 228-29.

12. W arde $P, O$ 'Sullivan $B, B$ ristow $R G$, et al. $T 1 / T 2$ glottic cancer managed by external beam radiotherapy: The influence of pretreatment hemoglobin on local control. Int J Radiat Oncol Biol Phys 1998;41:347-53.

13. Epstein BE, Lee DJ, Kashima H, Johns ME. Stage T1 glottic carcinoma: Results of radiation therapy or laser excision. Radiology 1990;175:567-70.

14. Cellai $E$, Chiavacci A, Olmi P. Causes of failure of curative radiation therapy in 205 early glottic cancers. Int J Radiat O ncol Biol Phys 1990;18:1307-13.

15. Fein DA, L ee W R, Hanlon AL. Do overall treatment time, field size, and treatment energy influence local control of T1-T2 squamous cell carcinomas of glottic larynx. Int J Radiat Oncol Biol Phys 1996;34:823-31.

16. M illion RR. Thelarynx... so to speak: Everything I want to know about laryngeal cancer I learned in the past 32 years. Int J R adiat Oncol Biol Phys 1992;23:691-704.

17. Sessions D G, Ogura JH, Fried M P. The anterior commissure in glottic carcinoma. Laryngoscope 1975;85:1624-32.

18. Overgarrd J, Alsner J, Eriksen J, et al. Importance of overall treatment time for the response to radiotherapy in patients with squamous cell carcinoma of the head and neck. Rays 2000;25(3):313-19.
19. Rudoltz MS, B enammar A, M ohiuddin M. Prognostic factors for local control and survival in T1 squamous cell carcinoma of the glottis. Int J Radiat Oncol Biol Phys 1993;26:767-72.

20. James ND, R obertson G, Squire CJ, Forbes H, J ones K, Cottier $B$. A national audit of radiotherapy fractionation in head and neck cancer. Clin Oncol 2003;15:41-46.

21. Short S, Krawitz $H, M$ acannn A, et al. T1N0/T2NO glottic carcinoma: A comparison of two fractionation schedules. A ustralas Radiol 2006;50:152-57.

22. Kim RY, M ark ME, Salter M M. Early stage glottic cancer: Importance of dose fractionation in radiation therapy. Radiology 1992;182:273-75.

23. Ricciardelli EJ, W eymuller EA J r, K oh WJ, A ustin-Seymour M, DeSautael M G, L aramore GE. Effect of radiation fraction size on local control rates for early glottis carcinoma. A model analysis for in vivo tumor growth and radio-response parameters. A rch Otolaryngol Head Neck Surg 1994;120:737-42.

24. Small W , M ital BB , B rand W N , et al. R esults of radiation therapy in early glottic carcinoma: M ultivariate analysis of prognostic and radiation therapy variables. Radiology 1992;183:789-94.

25. Wiernik G, A lcock CJ , B ates TD, et al. Final report on the second $B$ ritish Institute of Radiology fractionation study: Short versus long overall treatment times for radiotherapy of carcinoma of the laryngopharynx. Br J Radiol 1991;64:232.

26. Shimizu R. A n evaluation of absorbed doses of high energy electromagnetic radiation in radiotherapy of laryngeal cancer. Nippon Jibiinkoka Gakkai K aiho 1990;93:796-807.

27. A kine $Y$, Tokita N, O gino T, Tsukiyama I, et al. Radiotherapy of T1 glottic cancer with $6 \mathrm{M}$ eV X-rays. Int J Radiat O ncol Biol Phys 1993;26:767-72.

28. Foote RL, Grado GL, Buskirk SJ, et al. Radiation therapy for glottic cancer using 6-M V photons. Cancer 1996;77:381-86.

29. Steiner $W$. Results of curative laser microsurgery of laryngeal carcinomas. A m J Otolaryngol 1993:14;116-21.

30. Spector J G, Sessions DJ, Chao K S, et al. Stage (T 1 N O M 0) squamous cell carcinoma of the laryngeal glottis: Therapeutic results and voice preservation. Head Neck 1999;21:707-17.

31. A mbrosch P. The role of laser microsurgery in the treatment of laryngeal cancer. Curr Opin Otolaryngol Head Neck Surg 2007; 15:82-88.

32. Cohen SM, Garret CG, Dupont WD, Ossoff RH, Courey M S. Voice-related quality of life in T1 glottic cancer: Irradiation versus endoscopic excision. Ann Otol Rhinol Laryngol 2006;115:581-86.

33. Dinapoli N , Parrilla C, Galli J, et al. M ultidisciplinary approach in the treatment of $\mathrm{T} 1 \mathrm{glottic}$ cancer. The role of patient preference in a homogenous patient population. Strahlenther Onkol 2010;186(11):607-13. 